\title{
Engineering of protein nanocages for superlatttice formation and nanoparticle encapsulation
}

\section{Tobias Beck}

\author{
University of Hamburg, Hamburg, Germany \\ tobias.beck@chemie.uni-hamburg.de
}

Self-organization is a key tool for the construction of functional nanomaterials. We have recently established a novel method for the self-organization of biomolecular building blocks and nanoparticles. Towards this goal, protein containers, engineered with opposite surface charge, are used as an atomically precise ligand shell for the assembly of inorganic nanoparticles. ${ }^{[1]}$ The assembly of these protein-nanoparticle composites yields highly ordered nanoparticle superlattices with unprecedented precision. The structure of the protein scaffold can be tuned with external stimuli such as metal ion concentration. ${ }^{2]}$ Importantly, these composite materials show catalytic activity inside the porous material. ${ }^{[3]}$ Along these lines, the protein containers used as a scaffold offer a viable route towards renewable materials. ${ }^{[4]}$

For the formation of biohybrid materials, the inorganic cargo has to be encapsulated into the protein containers. Here, we demonstrate that the highly specific cargo-loading mechanism of the bacterial nanocompartment encapsulin can be employed for encapsulation of artificial cargo such as inorganic nanoparticles. ${ }^{[5]}$ For this purpose, gold nanoparticles were decorated with cargo-loading peptides. By lock-and-key interaction between the peptides and the peptide-binding pockets on the inner container surface, the nanoparticles are encapsulated with extremely high efficiency. Most notably, the supramolecular peptide binding is independent from external factors such as ionic strength. ${ }^{[5]}$ Cargo-loading peptides may serve as generally applicable tool for efficient and specific encapsulation of cargo molecules into a protein compartment. Moreover, these nanoparticle protein-container composites are suitable for applications as building blocks in materials, exploiting the plasmonic properties of gold nanoparticles for light manipulation or sensing.

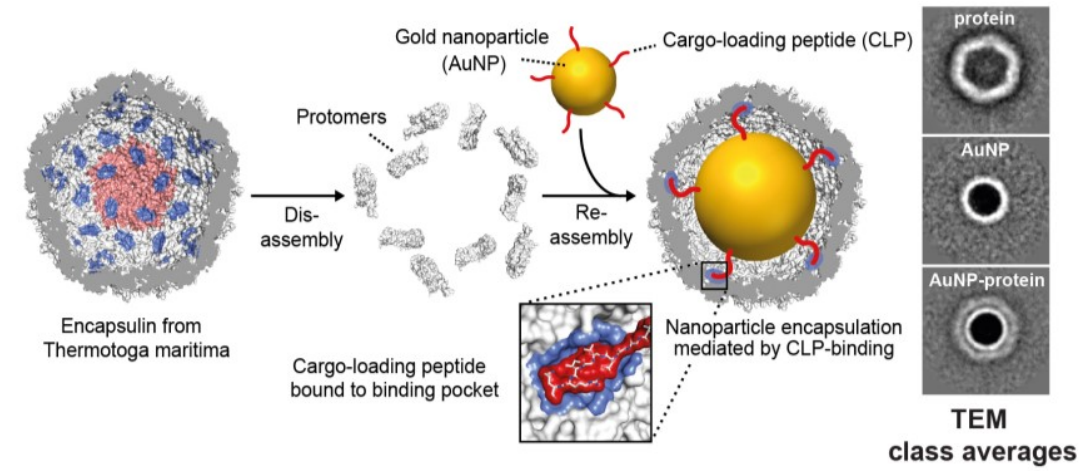

Figure 1. Self-assembly of protein-nanoparticle building blocks using supramolecular peptide binding

[1] M. Künzle, T. Eckert, T. Beck, J. Am. Chem. Soc. 2016, 138, 12731-12734.

[2] M. Künzle, T. Eckert, T. Beck, Inorg. Chem. 2018, 57, 13431-13436.

[3] M. Lach, M. Künzle, T. Beck, Chem. Eur. J. 2017, 23, 17482-17486.

[4] a) M. Künzle, M. Lach, T. Beck, Dalton Transactions 2018, 47, 10382-10387; b) M. Lach, M. Künzle, T. Beck, Biochemistry 2019, 58, $140-141$.

[5] M. Künzle, J. Mangler, M. Lach, T. Beck, Nanoscale 2018, 10, 22917-22926.

\section{Keywords: Protein engineering, Protein nanocages, Nanoparticles}

